Tânia Maria de Araújo (iD) https://orcid.org/0000-0003-2766-7799

Iracema Luab

(iD) https://orcid.org/0000-0002-5760-5073

aniversidade Estadual de Feira de Santana, Núcleo de Epidemiologia. Feira de Santana, BA, Brasil.

bUniversidade Estadual de Feira de Santana, Programa de Pós-graduação em Saúde Coletiva. Feira de Santana, BA, Brasil.

Contato:

Tânia Maria de Araújo

E-mail:

araujo.tania@uefs.br

As autoras declaram que o trabalho não foi subvencionado e que não há conflitos de interesses.

As autoras informam que o ensaio se baseia em apresentação realizada na Ágora - atividade organizada pela Associação Brasileira de Saúde Coletiva (Abrasco), ocorrida no dia 9 de julho de 2020.

\section{O trabalho mudou-se para casa: trabalho remoto no contexto da pandemia de COVID-19}

\author{
Work has moved home: remote work \\ in the context of the COVID-19 pandemic
}

\section{Resumo}

Objetivo: discutir os elementos vivenciados pelos(as) trabalhadores(as) com a ampla implementação de atividades laborais remotas, realizadas em casa, com auxílio das tecnologias de informação-comunicação, no contexto da pandemia de COVID-19. Métodos: com base em dados oficiais e revisão de literatura, discutemse características do trabalho remoto (TR) e suas potenciais repercussões, enfatizando-se questões de gênero. Resultados: medidas de controle e prevenção contra a COVID-19, sobretudo o distanciamento social, mudaram o cotidiano social e familiar. Uma parcela de trabalhadores(as) manteve suas atividades laborais em casa. O TR foi imposto sem as condições estruturais e de treinamento necessárias e intensificou os efeitos do trabalho sem limites temporais definidos. Em casa, novas demandas surgiram (acompanhamento escolar e aumento de demandas por higienização e limpeza). Discussão: com a perda de fronteiras, o mundo privado torna-se público, a casa é incorporada ao mundo do trabalho. Novas questões emergem. Quais demandas surgem nesse novo arranjo produtivo-reprodutivo? Quais alterações se produzem nas atividades domésticas e de cuidados da família? Essas questões tendem a perdurar, mesmo passada a situação crítica da pandemia. Parte desse modo de operar os processos de trabalho permanecerá, e a vida em sociedade será modulada por essas transformações. Esses desafios deverão mobilizar atenção e intervenção.

Palavras-chave: saúde do trabalhador; condições de trabalho; trabalho remoto; iniquidade de gênero; trabalho doméstico.

\begin{abstract}
Objective: to discuss the workers' experiences with the wide implementation of remote work activities, carried out at home, using information-communication technologies, in the context of the COVID-19 pandemic. Methods: based on official data and literature review, we discussed the characteristics of remote work (RW) and its potential repercussions, emphasizing gender issues. Results: control and prevention measures against COVID-19, especially social distance, changed social and family life. Part of the workers kept engaged in their work activities at home. $R W$ was imposed even without the necessary structure and training conditions, intensifying the effects of the working hours without defined limits. At home, new demands were put forward (educational support for children and increased housework). Discussion: by losing its borders, the private world becomes public; the household is incorporated into the world of work. New questions emerge. What demands rise from this new productive-reproductive arrangement? What changes take place in household and family care activities? These issues tend to persist, even after the critical situation of the pandemic. Part of this way of operating work processes will remain and life in society will be shaped by these changes. These challenges should demand attention and interventions.
\end{abstract}

Keywords: occupational health; working conditions; remote work; gender inequality; housework. 


\section{Introdução}

Os temas tratados neste ensaio não são novidade. Trabalho em casa, conciliação dos períodos de trabalho e de cuidados da casa e família são velhos dilemas da vida, sobretudo na vida das mulheres ${ }^{1-3}$. É um assunto antigo, mas é também atual, porque a pandemia de COVID-19 tem iluminado um conjunto amplo de problemas ainda invisibilizado.

As transformações geradas pela revolução industrial do século XIX - que criou a fábrica e forjou a separação dos mundos privado e público, de vida produtiva (trabalho remunerado) e reprodutiva (atividades domésticas e de cuidado), e que cindiu e aprisionou o afeto na família - são colocadas agora de ponta cabeça. O trabalho, impedido de ocorrer no espaço da "fábrica", foi obrigado a buscar novo endereço; mudou-se para a casa. Na casa, reorganizou a vida e amplificou uma parte quase invisível da vida social: o trabalho envolvido na reprodução, agora em disputa direta, no mesmo espaço e tempo, com o trabalho produtivo.

Como visitante não programado, chegou sem aviso, arrumação ou organização prévias. Tudo feito no improviso. Trabalho profissional e trabalho de casa, agora sem espaços claros de pertencimento e delimitação temporal, embaralham e prolongam as jornadas laborais. Além de realizar algo inédito, estabelece condições que nos revelam: por meios tecnológicos, torna público, acessível ao olhar do outro, o que era privativo, promovendo uma certa condição de intimidade desprotegida. É na nossa casa, com nossa família, com nossos animais de estimação e com os sons da nossa vizinhança que o trabalho se implanta e torna boa parte disso visível ao outro: uma porta se abre na tela do computador e nos invade, permitindo o acesso a um mundo privado, pessoal e, até então, protegido na nossa intimidade.

Nesse contexto da pandemia de COVID-19, a casa viu-se transformada em espaço público. Mas as mudanças abruptas que ocorreram não se restringiram a isso: as invasões, demandas e exigências foram também multiplicadas. Por exemplo, a jornada de trabalho sem limites temporais somou-se às exigências de provisão dos meios e ferramentas para o trabalho remoto (como internet, computador e celular) e de capacitação para operar os dispositivos eletrônicos necessários à conexão com o mundo externo, assim como às medidas de distanciamento físico e permanência em casa. Nesse cenário, uma dupla tensão ocorre: por um lado, multiplicam-se as exigências, sem o devido preparo e treinamento; por outro, as zonas de escape das tensões sofreram limitações drásticas, em função da restrição da circulação e das relações e contatos sociais. A redução dos salários e a ameaça de perda do emprego adicionam novos elementos na dramaticidade da situação. Juntos e sobrepostos, todos esses fatores parecem ameaçar de vez a capacidade de trabalho e a sanidade mental de trabalhadores(as).

Neste ensaio, uma nota inicial é necessária. A definição de trabalho não se restringe ao conceito de trabalho remunerado (relativo à esfera produtiva), mas envolve a esfera da reprodução social (trabalho doméstico). O ponto de partida para as reflexões sobre o trabalho em casa adota uma posição histórica defendida desde a década de 70, com esforços iniciados na França, que norteou uma tradição de pesquisas nessa direção ${ }^{4}$. Nessa perspectiva, amplia-se também o conceito de jornada de trabalho.

O conceito jurídico de jornada de trabalho refere-se ao tempo no qual o trabalhador está à disposição da empresa; reportando-se ao tempo de trabalho comprado pelo capitalista ${ }^{5}$. A vinculação teórico-conceitual de "jornada de trabalho" ao âmbito produtivo é perpetuada pela aliança entre interesses da acumulação capitalista e do poder patriarcal ${ }^{6}$, reforçando a dimensão de tempo laboral apenas na esfera produtiva (espaço masculino e de produção de mais valia). Por outro lado, o trabalho doméstico, executado majoritariamente pelas mulheres e sem fins lucrativos, comumente não é visto como trabalho ${ }^{6}$. Essa restrição fomentou as proposições de defesa da inclusão da dimensão do trabalho doméstico ao conceito, e da necessidade de consideração das jornadas/ cargas totais de trabalho ${ }^{4}$.

Com base na divisão sexual do trabalho, essas duas jornadas laborais (profissional e doméstica) conformam realidades nas vidas das mulheres ${ }^{7}$, sustentadas por mecanismos diversos de dominação masculina ${ }^{8}$ e de relações de poder ${ }^{9}$. Além disso, Ávila ${ }^{10}$ chama a atenção para o fato de que a expressão "dupla jornada de trabalho" não caracteriza a presença de jornadas isoladas, mas sim de jornadas que se sobrepõem, tornando-se intensivas, extensivas e intermitentes ${ }^{7}$. Esses são aspectos relevantes na análise do trabalho produtivo que migra para o lócus da casa, causando uma justaposição sem precedentes dessas jornadas laborais.

O propósito deste ensaio é discutir os elementos vivenciados pelos(as) trabalhadores(as) com a implementação ampliada de atividades laborais remotas, realizadas em casa, com o auxílio das tecnologias de informação-comunicação, no contexto da pandemia de COVID-19. Pretendeu-se elencar as características desse tipo de trabalho, com base no que é possível mapear atualmente, e discutir as suas repercussões potenciais, com ênfase nas questões de gênero. Na sua elaboração, realizou-se levantamento de literatura com uso dos descritores teleworking, telework, mobile work, home office, home working, remote work e COVID-19. Selecionaram-se textos que discutiam as características do trabalho remoto (TR) e suas potenciais repercussões. Dados de 
pesquisas oficiais nacionais e internacionais foram incorporados, como a Pesquisa Nacional por Amostra de Domicílios (PNAD) COVID-1911.

\section{Trabalho em casa: teletrabalho, trabalho remoto}

A literatura registra o uso de diferentes termos para o trabalho realizado em casa. A definição dos conceitos nesse campo é diversa e apresenta modificações temporais significativas. Assim, inúmeras propostas conceituais e vocabulares estão disponíveis ${ }^{12}$. Na opção conceitual adotada neste ensaio, registra-se que, ainda que atualmente os conceitos de teletrabalho e TR sejam tratados como sinônimos, na definição conceitual estrita entende-se que são termos distintos.

O trabalho executado fora da "fábrica" (local de trabalho, de propriedade do(a) empregador(a), destinado ao trabalho e consumo da jornada laboral), no recorte deste ensaio, envolve conceitos de TR, teletrabalho ou trabalho a distância. Esses conceitos não são novos, embora uma série de elementos inaugurais possa ser identificada atualmente. Em 1962, uma empresa inglesa, com a finalidade de reduzir a rotatividade de mulheres empregadas em serviços de programação, instituiu o trabalhar em casa, iniciando, assim, uma das primeiras experiências desse tipo de trabalho, com base no emprego da tecnologia ${ }^{13}$. Adiante, nos anos 1970, registrou-se o primeiro uso do termo teletrabalho ${ }^{14}$. Mas o termo se popularizou a partir da publicação do livro The Telecommunications-Transportation Tradeoff $f^{15}$, que teve Jack Nilles como um de seus autores - Nilles é ex-engenheiro da NASA e trabalhou em alternativas para o transporte, considerando problemas decorrentes do tráfego, expansão e escassez de recursos não renováveis. Na definição de Nilles ${ }^{15}$, teletrabalho é o trabalho que permite alcançar seus resultados usando tecnologia da informação, como telecomunicações e computadores, em vez de movimento físico das pessoas. Assim, corresponde à "possibilidade de enviar o trabalho ao trabalhador em lugar de enviar o trabalhador ao trabalho" (p. 87).

As primeiras experiências mais amplas desse modelo de trabalho foram feitas no início dos anos 1990, na empresa americana AT\&T, utilizando-se um sistema de teletrabalho que chegou a ocupar $55 \%$ dos funcionários das suas filiais nos EUA ${ }^{16}$. Um conjunto de análises feitas naquela década a respeito desse novo modelo de organização e gestão deu relevo, sobretudo, aos seus benefícios para os funcionários e organizações: aumento da produtividade, redução do absenteísmo e das despesas gerais, tornando os regulamentos ambientais mais fáceis de serem cumpridos ${ }^{17}$.
Teletrabalho refere-se a um contrato que estabelece a realização do trabalho fora da empresa contratante, sendo uma forma de emprego flexível. No Brasil, o teletrabalho foi introduzido na reforma trabalhista de 2017, quando se regulamentou o trabalho intermitente - uma modalidade de contratação que permite que a empresa admita um funcionário para trabalhar eventualmente e o remunere apenas por esse período. Na legislação, teletrabalho é definido como "[...] prestação de serviços preponderantemente fora das dependências do empregador, com utilização de tecnologias de informação e comunicação que, por sua natureza, não se constituam como trabalho externo" (art. 75-B da Lei n ${ }^{\circ} 13.467$, de 2017 $)^{18}$. Nessa regulamentação da modalidade, não há controle de jornada laboral e não há direito ao adicional de horas extras, intervalo intrajornada e interjornada - o controle da jornada é do(a) trabalhador(a).

O TR é feito a qualquer distância do local onde seus efeitos são esperados ou é realizado como parte de um tradicional sistema de emprego, usando as técnicas disponíveis de tecnologia da informação ${ }^{19}$. O termo inglês home-office tem sido generalizado para descrever esse tipo de trabalho que é realizado de maneira remota e eventual na residência do empregado.

Um aspecto destacado na análise dessas modalidades de trabalho é a ambiguidade a respeito de suas características, com listagem de vantagens e desvantagens. Registra-se, ainda, o papel da mídia no esforço por apresentar esse tipo de trabalho como uma espécie de oportunidade para a liberdade e autonomia pessoal ("você como o dono do seu tempo"). A percepção sobre isso, no entanto, depende de características como gênero, composição familiar, tipo de ocupação, entre outras.

A pandemia trouxe uma realidade global com alterações constantes, exigindo adaptações contínuas. A intensidade do TR na pandemia aumentou significativamente. Apesar da ausência de evidências empíricas consolidadas, as condições ocupacionais nesse cenário são peculiares. É importante lembrar que essas alterações ocorrem em um momento marcado por medidas de afastamento social e em que se espera consequências econômicas negativas, recessão sem precedentes, declínio econômico, demissões e aumento do desemprego. Esses fatores, por si só, podem despertar medo e ansiedade quanto ao futuro e afetar a qualidade do TR e da vida das pessoas. No contexto brasileiro, somam-se ainda as crises superpostas (econômica, política, social e ampla desproteção do trabalho após as reformas trabalhista e previdenciária) e as restrições de circulação e contatos, tornando o TR uma das poucas possibilidades de relações sociais fora de casa. Mas os efeitos dessas relações dependem de sua atuação como fonte de apoio ou de pressão. 


\section{Qual a dimensão do trabalho remoto no Brasil durante a pandemia de COVID-19?}

Para o controle da pandemia de COVID-19, foram adotadas medidas de distanciamento social, com restrição de circulação, fechamento de escritórios, comércio, escolas e faculdades. O TR foi a alternativa encontrada para a continuidade das atividades laborais. Serviços administrativos e escolares foram aqueles de maior incremento dessa modalidade de trabalho. Estudos em várias partes do mundo evidenciam esse aumento durante a pandemia.

Estudo na Polônia ${ }^{20}$ confirma aumento vertiginoso do TR, conjugado ao despreparo de empresas e trabalhadores(as) para esse tipo de trabalho. Antes da pandemia, trabalhavam em TR: até 5 dias, 1,9\%; de 3 a 4 dias, 4,0\%; TR esporádico, 43,4\%. Enquanto isso, $33,9 \%$ nunca tiveram TR. A situação na pandemia alterou-se radicalmente: $85,6 \%$ trabalhavam 5 dias em TR. Há peculiaridades no perfil de quem se inseriu nessas atividades: $69 \%$ estavam no setor de serviços; $73 \%$ trabalhavam em empresas grandes, $13,5 \%$ em médias, $9 \%$ em pequenas e $4,5 \%$ em microempresas. Além disso, verificou-se a maior frequência do TR entre as mulheres (58\%) e pais com filhos menores de 18 anos (61\%).

Nos Estados Unidos, um inquérito realizado em abril de 2020 com 25.000 trabalhadores(as) observou que quase metade destes estava trabalhando em casa $(48,7 \%): 34,1 \%$ passaram a trabalhar durante a pandemia e $14,6 \%$ trabalhavam desse modo previamente ${ }^{21}$.

No Brasil, dados da PNAD COVID-19 de maio de $2020^{11}$ mostram contexto geral muito precário: entre ocupados(as) que estavam afastados(as) do trabalho (considerando a semana de referência: 19,0 milhões), aproximadamente 9,7 milhões estavam sem a remuneração do trabalho - representando $51,1 \%$ das pessoas afastadas do trabalho ou $11,5 \%$ do total de ocupados. As regiões Nordeste e Norte apresentaram os maiores percentuais de pessoas afastadas do trabalho e sem remuneração: $55,3 \%$ e $53,2 \%$, respectivamente. Este é um cenário que exerce intensa pressão sobre quem manteve seu trabalho e salário. A ameaça do desemprego emerge como um mal maior nas tensões atuais.

Do total de ocupados no Brasil, em maio de 2020 (84,4 milhões), 77,5\% (65,4 milhões) não estavam afastados do trabalho; dentre estes, $13,3 \%$ (8,7 milhões) estavam trabalhando de forma remota (home-office). O percentual de mulheres em TR foi de 17,9\%, superior ao registrado para os homens (10,3\%); não houve grandes disparidades por grupos etários (14-29 anos: 11,7\%; 30-49 anos: 14,4\%; 50-59 anos: 12,0\%; 60 anos ou mais: $14,3 \%)$. Por escolaridade, quanto maior o nível de instrução, maior o percentual em TR: 0,6\% entre pessoas sem instrução, com fundamental completo ou incompleto; $1,7 \%$ entre aqueles com nível médio incompleto. Entre aqueles com ensino médio completo e/ou superior incompleto, o percentual foi de 7,9\%; com nível superior completo e/ou pós-graduação, foi de $38,3 \%{ }^{22}$.

Os dados da PNAD COVID-19 de julho de $2020^{23}$ (cerca de cinco meses de pandemia) confirmam esse perfil do TR, além de evidenciar desigualdades regionais, sociais e ocupacionais. A proporção das pessoas ocupadas em TR sofreu queda lenta: 13,3\% na média de maio para $12,4 \%$ em junho; $11,7 \%$ em julho; 11,5\% em agosto (mantendo-se estável nas últimas três semanas de agosto). A distribuição segundo nível de escolaridade mantém-se como comentado acima, quanto maior o nível de escolaridade, maior a proporção de pessoas em TR. As ocupações mais qualificadas também foram aquelas com maior proporção de TR: profissionais das ciências e intelectuais representaram $50 \%$ em TR, enquanto trabalhadores elementares (não qualificados) e operadores de instalações, máquinas e montadores, as proporções corresponderam a $0,9 \%$ e $0,4 \%$, respectivamente (Tabela 1). As diferenças regionais também persistem, com as regiões mais ricas apresentando as maiores proporções de trabalhadores(as) nessas atividades: na região Sudeste representam 13\% e na região Norte, 4\% (Tabela 2 ).

Com relação às disparidades, os dados da PNAD COVID-19 ${ }^{23}$ evidenciam ainda dois aspectos. O primeiro refere-se aos diferenciais de acesso e qualidade da internet nas regiões mais ricas e de predominância de trabalho informal nas regiões mais pobres. No segundo trimestre de 2020, o trabalho informal, na região Sudeste, correspondia a 31,5\%, enquanto na região Norte chegava a 57,9\% da população ocupada $^{11}$. Na informalidade estão as atividades com baixo uso de tecnologias (necessárias ao trabalho em casa) e de prestação de serviços que exigem a presença para sua realização, como a agricultura, trabalhos domésticos e comércio informal de rua. Isso pode ajudar a explicar as diferenças de TR das regiões brasileiras: quanto menor o nível de qualificação e maior precariedade do trabalho, menor a implementação e uso do TR. O segundo aspecto refere-se à maior proporção de TR em ocupações tradicionalmente desempenhadas pelas mulheres (educação, ciências e apoio administrativo), o que reforça configurações sociais que afirmam uma maior compatibilidade do espaço privado ao trabalho feminino e permitem ajustes das atribuições domésticas e familiares. Ou seja, reforçam características tradicionais da divisão sexual do trabalho e de sua valorização e reconhecimento social. 
Tabela 1 Estimativas de população ocupada* e em trabalho remoto** durante a pandemia de COVID-19, segundo a ocupação, Brasil, 2020

\begin{tabular}{lcc}
\hline \multicolumn{1}{c}{ Ocupação } & População ocupada (\%) & Em trabalho remoto (\%) \\
\hline Profissionais das ciências e intelectuais & 13,1 & 50,0 \\
Trabalhadores de apoio administrativo & 7,0 & 10,6 \\
Técnicos e profissionais de nível médio & 6,3 & 9,0 \\
Diretores e gerentes & 3,5 & 8,0 \\
Trabalhadores dos serviços, vendedores de comércio e mercados & 16,6 & 5,4 \\
Trabalhadores qualificados, operários e trabalhadores da construção, & 12,5 & 1,2 \\
das artes mecânicas e outros ofícios & 14,0 & 0,9 \\
Trabalhadores elementares (não qualificados) & 7,9 & 0,4 \\
Operadores de instalações, máquinas e montadores & 6,6 & 0,2 \\
Trabalhadores qualificados da agropecuária, florestais, da caça e pesca & 12,5 & 14,3 \\
Outras & 100,0 & 100,0 \\
Total & & \multirow{2}{*}{. } \\
\hline
\end{tabular}

*População ocupada: $\mathrm{N}=84,4$ milhões; **Trabalhadores em trabalho remoto: $\mathrm{N}=8,7$ milhões.

Fonte: IBGE, PNAD COVID-19, maio $2020^{11}$

Tabela 2 Presença do trabalho remoto, no contexto da pandemia de COVID-19, em cada região do Brasil (2020)

\begin{tabular}{lcc}
\hline Regiões do país & População ocupada (milhões) & Em trabalho remoto (\%)* \\
\hline Sudeste & 36,7 & 13,0 \\
Sul & 13,5 & 9,0 \\
Centro-Oeste & 7,0 & 9,0 \\
Nordeste & 17,9 & 7,8 \\
Norte & 6,2 & 4,0 \\
\hline
\end{tabular}

*Estimativa de percentuais (\%) considerando o total de pessoas ocupadas e não afastadas do trabalho em cada região.

Fonte: IBGE, PNAD COVID-19, maio $2020^{11}$

\section{Características do trabalho remoto}

Na literatura recente $\mathrm{e}^{20,24-33}$, a discussão centra-se no levantamento das vantagens (aspectos positivos) e desvantagens (aspectos negativos) do teletrabalho ou atividades remotas (home-office), com relevo dos pontos positivos (Tabela 3). A positividade parece estar associada a três aspectos: a) grande parte das pesquisas examina a eficácia e o impacto do TR no desempenho organizacional, mas não incorpora ou examina a perspectiva do(a) trabalhador(a); b) negligência das questões de gênero - poucas vezes citadas ou analisadas; c) foco na perspectiva econômica: diante da situação de pandemia e da crise financeira associada, o(a) trabalhador(a) fica entre o desemprego, o trabalhar em casa e o trabalhar presencialmente com risco de exposição ao vírus. Nesse contexto de crise, a possibilidade de opção pelo TR ganha ares de privilégio. Contudo, com base nas pistas que se pode reunir até aqui, na prática, a realidade está distante disso.

Um olhar mais atento sobre a implantação desse tipo de trabalho e as condições existentes para sua execução permite constatar que, ao mesmo tempo que criou situação protegida contra a COVID-19, também inaugurou demandas e exigências, em condições laborais não reguladas, com potencial de incrementar os riscos ocupacionais e a ocorrência de adoecimento, como as LER/DORT e os transtornos mentais relacionados ao trabalho. Isso se agrava com a responsabilidade, remetida aos trabalhadores(as), de prover as condições de trabalho e situações seguras para o exercício profissional.

As características dessa nova configuração de trabalho (Tabela 3), marcadas pela invasão abrupta do espaço doméstico e familiar pelo trabalho profissional, são experimentadas de diferentes formas, a depender das circunstâncias vivenciadas na esfera produtiva e reprodutiva. A sua vivência atrela-se às perspectivas e possibilidades de cada grupo social e ocupacional e aos recursos e acessos disponíveis. Como apontado, diversos fatores podem dificultar a execução do TR, a exemplo da presença de filhos pequenos, idosos ou doentes em casa; estruturas espaciais e de mobiliário inadequadas (local, equipamentos, internet); ausência de experiência anterior no uso das tecnologias necessárias ${ }^{20}$. Essas condições, por sua vez, são determinadas pelo acesso ou exclusão dominante na estrutura social estabelecida. O conjunto de informações disponíveis até o momento alerta para a possibilidade de aprofundamento das desigualdades de classe, de gênero, de geração e de raça/cor da pele no mundo do trabalho com a implantação das atividades remotas. 
Tabela 3 Aspectos positivos e negativos do trabalho remoto no contexto da pandemia de COVID-19 (2020)

\begin{tabular}{|c|c|}
\hline Referências & Aspectos positivos \\
\hline $\begin{array}{l}\text { Alon, Doepke, Olmstead-Rumsey e Tertilt }{ }^{24} \\
\text { Himawan, Fanggidae e Helmi }{ }^{25} \\
\text { Kaushik e Guleria }^{26} \\
\text { Mungkasa }{ }^{27} \\
\text { Wolor et al. }^{28}\end{array}$ & $\begin{array}{l}\text { Permite gerenciar o trabalho com flexibilidade, podendo contribuir para melhor } \\
\text { conciliação entre trabalho profissional e a vida familiar. }\end{array}$ \\
\hline $\begin{array}{l}\text { Kaushik e Guleria }{ }^{26} \\
\text { Mungkasa }^{27}\end{array}$ & $\begin{array}{l}\text { Reduz o tempo de transporte trabalho-casa, a poluição ambiental pelo uso de } \\
\text { combustíveis fósseis e contribui para a economia de combustível. }\end{array}$ \\
\hline $\begin{array}{l}\text { Kaushik e Guleria }{ }^{26} \\
\text { Mungkasa }^{27}\end{array}$ & Flexibiliza o trabalho: pode-se trabalhar onde, quando e como preferir. \\
\hline Kaushik e Guleria ${ }^{26}$ & Possibilita distanciamento social aos trabalhadores que sofrem de ansiedade social. \\
\hline \multirow[t]{2}{*}{ Kaushik e Guleria ${ }^{26}$} & Aumenta a produtividade. \\
\hline & Aspectos negativos \\
\hline $\begin{array}{l}\text { Mungkasa }{ }^{27} \\
\text { Putro e Riyanto }\end{array}$ & $\begin{array}{l}\text { Ausência de contato direto com colegas e exclusão de situações de convívio } \\
\text { (café, pequenas reuniões, conversas casuais), reconhecidas por reduzir a } \\
\text { preocupação e melhorar desempenho. }\end{array}$ \\
\hline $\begin{array}{l}\text { Dolot }^{20} \\
\text { Putro e Riyanto } \\
\text { Gondim e Borges } \\
\text { Go }^{30}\end{array}$ & $\begin{array}{l}\text { Sensação de isolamento, solidão e alienação; ausência de apoio social e ajuda no } \\
\text { trabalho; frustração e sentimentos de isolamento profissional. }\end{array}$ \\
\hline $\begin{array}{l}\text { Dolot }^{20} \\
\text { Mungkasa }^{27}\end{array}$ & $\begin{array}{l}\text { Impacto nas relações com vizinhos e familiares em função da estigmatização social: } \\
\text { quem fica em casa tende a parecer desempregado(a). }\end{array}$ \\
\hline Mungkasa $^{27}$ & $\begin{array}{l}\text { Aumento de conflitos em casa, quando não participam do trabalho doméstico e } \\
\text { atividades familiares, apesar de estarem em casa. }\end{array}$ \\
\hline $\begin{array}{l}\text { Dolot }^{20} \\
\text { Himawan et al. }^{25} \\
\text { Wolor et al. }^{28} \\
\text { Putro e Riyanto } \\
\text { Cho }^{29}\end{array}$ & $\begin{array}{l}\text { Perda de fronteiras entre vida de trabalho e pessoal. } \\
\text { Impactos no uso do tempo, nas rotinas de trabalho remunerado e doméstico e demais } \\
\text { atividades realizadas em casa (sono, descanso, lazer, cuidado de si). }\end{array}$ \\
\hline $\begin{array}{l}\text { Dolot }^{20} \\
\text { Mungkasa } \\
\text { Wolor et al. }\end{array}$ & $\begin{array}{l}\text { Perda de controle sobre a jornada de trabalho, deixando a sensação de estar o tempo } \\
\text { todo no trabalho: ausência de pausas, trabalho noturno e nos fins de semana. }\end{array}$ \\
\hline $\begin{array}{l}\text { Mungkasa }{ }^{27} \\
\text { Wolor et al. } \\
\text { Gondim e Borges } \\
\text { Go }\end{array}$ & $\begin{array}{l}\text { Inadequações técnicas e estruturais que são repassadas para o(a) trabalhador(a) } \\
\text { resolver, uma vez que as atividades e as tarefas não estavam desenhadas para serem } \\
\text { executadas a distância. }\end{array}$ \\
\hline $\begin{array}{l}\text { Dolot }^{20} \\
\text { Mungkasa } \\
\text { Gondim e Borges } \\
\text { Bouziri et al. } \\
\text { Lord } \\
\text { Lord }^{33}\end{array}$ & $\begin{array}{l}\text { Dificuldade de concentração devido à presença e às demandas de outros } \\
\text { membros da família. Os espaços familiares não estão adaptados, } \\
\text { nem são adequados ao trabalho profissional. }\end{array}$ \\
\hline Lord 33 & $\begin{array}{l}\text { Pode contribuir para a crescente precariedade do trabalho, deslocando o custo do } \\
\text { espaço de trabalho de empregadores/as para empregados/as. }\end{array}$ \\
\hline $\begin{array}{l}\text { Himawan et al. }{ }^{25} \\
\text { Mungkasa } \\
\text { Lord }^{33}\end{array}$ & $\begin{array}{l}\text { Aumento dos custos das famílias com eletricidade, água, internet, alimentação e com } \\
\text { a aquisição de computadores, monitores, contratação de internet, que se juntam ao } \\
\text { temor de perder vantagens como vale transporte e auxílio alimentação. }\end{array}$ \\
\hline $\begin{array}{l}\text { Dolot }^{20} \\
\text { Himawan et al. } \\
\text { Wolor et al. } \\
\text { Wondim e Borges } \\
\text { Go }\end{array}$ & $\begin{array}{l}\text { Uso de mobiliário inadequado pode favorecer as posturas inadequadas e pior } \\
\text { condição ergonômica que, associadas à ausência de pausas e longas jornadas podem } \\
\text { produzir dor e distúrbios musculoesqueléticos. }\end{array}$ \\
\hline Dolot $^{20}$ & $\begin{array}{l}\text { Reduz o conforto da casa (que deixa de ser apenas espaço doméstico), restringindo-se } \\
\text { as possibilidades de relaxamento, lazer e de descanso. }\end{array}$ \\
\hline
\end{tabular}


Com relação ao gênero, é provável que a ausência de fronteiras de tempo e espaço entre as funções seja ainda mais perturbadora para quem responde pelas demandas familiares ${ }^{31}$. É provável, então, que o TR seja mais prejudicial às mulheres ${ }^{24}$, sobretudo para aquelas com crianças pequenas ${ }^{20,34}$ e para mães solteiras ${ }^{24}$. Estudos empíricos corroboram essa hipótese. Entre trabalhadores(as) da Bélgica, quem tinha crianças em casa estava menos satisfeito com $\mathrm{TR}^{34}$; na Polônia, $82 \%$ das mulheres mães de crianças pequenas indicaram dificuldades de $\mathrm{TR}^{20}$.

Portanto, é crível que o TR, nesse contexto, adicione encargos desproporcionais às mulheres ${ }^{35} \mathrm{e}$ amplie as desigualdades de gênero dentro e fora do mercado de trabalho formal, reforçando as distinções sexuais na inserção do trabalho, na precarização e na valorização social e econômica, uma vez que a falta de política institucional de apoio durante a pandemia reinscreve e privilegia um trabalhador "ideal” masculino ${ }^{36}$.

\section{Trabalho remoto e diferenciais de gênero no contexto de pandemia}

Embora a possibilidade de conciliar trabalho profissional e atividades familiares seja um dos itens mais citados como vantagens do TR, a abordagem desse tema quase nunca incluiu análise de aspectos relativos ao gênero, raça ou classe social ${ }^{26-28}$. Quando se faz menção às mulheres, reforça-se a perspectiva positiva de conciliação entre trabalho profissional e doméstico: como ambos passam a ocupar o mesmo espaço, as duas funções podem ser executadas ao mesmo tempo ${ }^{25,33}$.

Contudo, a avaliação adequada dos impactos do TR deve considerar que: 1) em todo o mundo, as mulheres são as principais responsáveis pelo trabalho doméstico, o que já dificultava sua inserção no mercado de trabalho ou conciliação entre essas duas funções; 2) a conciliação entre o trabalho familiar e profissional está particularmente afetada durante a pandemia, seja pelo fechamento de escolas e creches, pela suspensão das atividades das cuidadoras profissionais (diaristas, trabalhadoras domésticas e babás) ou pelo distanciamento de parentes, amigos e/ou vizinhos que auxiliavam como cuidadores informais ${ }^{24,26}$. Sem surpresa, esse trabalho doméstico extra, produzido pela pandemia, recaiu sobre as mulheres, exacerbando as desigualdades de gênero na divisão do trabalho doméstico nas famílias $^{36}$. Além disso, 3) é provável que mais mulheres enfrentarão a perda de emprego, seja pela esperada redução de empregos no setor de serviços, que tem predomínio feminino (educação, alimentação, hotelaria, comércio), ou pela necessidade de que um dos cônjuges pare de trabalhar para assumir as atividades domésticas extras ${ }^{24}$.
Portanto, as diferenças substantivas no TR para homens e mulheres podem resultar em maior conflito entre trabalho e família, não em equilíbrio. $\mathrm{O}$ aumento das demandas de cuidados infantis, incluindo as atividades de ensino, com pouco espaço para arranjos alternativos e apoio social, tem grande impacto para as mulheres ${ }^{24,37}$ e ampliam os já existentes conflitos trabalho-família. Soma-se a isto o aumento da necessidade de atividades domésticas durante a pandemia, porque mais pessoas estão doentes e precisam de cuidados e há necessidade de limpeza contínua, não apenas do ambiente da casa, mas de tudo que chega na casa (alimentos e embalagens, por exemplo).

Evidências de estudos de uso do tempo para atividades remuneradas e não remuneradas antes da pandemia de COVID-19 mostram disparidades expressivas de gênero: em quase todos os países da América Latina, em 2013, as mulheres apresentavam maior média de horas de trabalho total (formal e doméstico), com dados que revelam o dobro, ou mais, desse tempo para as mulheres, chegando ao triplo no México e ao quádruplo na Colômbia, no Equador e no Peru. Reflexo da realização do trabalho doméstico, quase exclusivamente, pelas mulheres, apesar de sua participação crescente no mercado de trabalho formal ${ }^{38}$. Dado esse contexto prévio desfavorável às mulheres, cabe indagar se, com a mudança do trabalho para a casa, essa distribuição do trabalho na família está sendo alterada, tornando-se mais equânime ou causando novos conflitos na negociação de fronteiras entre trabalho e família.

Durante a pandemia de COVID-19, uma proporção maior de mães do que pais declarou dificuldades no TR em função da necessidade de cuidar das crianças ${ }^{19}$. Os estudos, apesar de iniciais, reiteram a ampliação da divisão desigual de trabalho doméstico por gênero.

A sobreposição/conflito de funções profissionais e familiares, associada ao aumento das demandas e à falta de apoio, acrescem e intensificam estressores e riscos psicossociais ${ }^{28,30}$, que podem produzir sofrimento psíquico e transtornos mentais ${ }^{29}$. Há evidências de associação entre conflito trabalho-família e consumo abusivo de álcool, transtornos alimentares, exaustão, ansiedade, depressão e distúrbios do sono ${ }^{39}$.

Outro ponto que merece reflexão são as repercussões das tensões familiares e ocupacionais (que agora se confundem) e das consequências psíquicas para a ocorrência de violência intrafamiliar. O TR associado às medidas de distanciamento social elevam o tempo de convívio dentro da casa, estando relacionado ao aumento da violência doméstica durante a pande$\mathrm{mia}^{40}$, com destaque para aquela provocada pelo parceiro íntimo. Essa é uma tendência global, com vários países reportando mais denúncias de violência 
doméstica ${ }^{41}$. No Brasil, levantamento realizado pelo Fórum Brasileiro de Segurança Pública ${ }^{42}$ indica que a Polícia Militar do Estado de São Paulo registrou incremento de 44,9\% no atendimento de mulheres vítimas de violência e de 46,2\% de casos de feminicídio. Esses dados fortalecem relatos da literatura de intensificação da violência doméstica durante desastres e crises ${ }^{35}$.

O impacto do TR na evolução das carreiras profissionais é outro aspecto relevante. Com o trabalho remunerado e doméstico ocupando o mesmo ambiente, os seus limites ficam obscurecidos e, se as mulheres continuam se ocupando de uma fatia ainda maior das tarefas domésticas e familiares, é provável que essas mudanças afetem o trabalho e os resultados profissionais de diferentes maneiras ${ }^{31}$. A redução da produtividade entre as mulheres pode ter impacto nas carreiras femininas presente e futura ${ }^{43}$.

Um exemplo disso tem sido descrito no desempenho e produção científica. Dados iniciais evidenciam ampliação de disparidades de gênero das atividades por TR. Como descrito na Tabela 1, os profissionais das ciências e intelectuais registraram a maior proporção de TR. Esses postos de trabalho têm percentual expressivo de mulheres (atividades nas universidades). As distinções de ingresso e reconhecimento na vida acadêmica, já identificadas entre homens e mulheres ${ }^{44}$, parecem estar se somando à redução da produtividade acadêmica na situação de TR. Os dados mostram que COVID-19 afeta sobremaneira a publicação das pesquisadoras. Atividades de leitura, análise de textos, levantamento e tratamento de dados, redação e correção de artigos científicos exigem concentração duradoura, o que é dificultado em situações de sobreposição de atividades produtivas e domésticas em um mesmo espaço ${ }^{45}$. A redução na produção científica, com decréscimo do número de artigos produzidos pelas pesquisadoras, atesta o problema e fortalece a urgência de seu enfrentamento. Anderson et al. ${ }^{46}$ analisaram 1.893 artigos médicos relacionados à pandemia, em comparação aos artigos publicados nos mesmos periódicos em 2019, e concluíram que a proporção de artigos com uma mulher como primeira autora foi $19 \%$ menor do que para artigos publicados nas mesmas revistas em 2019.

\section{Considerações finais: reflexões sobre os aspectos críticos e perspectivas}

Como explorado acima, as dimensões de gênero na crise sanitária gerada pela pandemia de COVID-19 aplicam-se também "dentro" de casa, onde a divisão desigual de trabalho doméstico por gênero persiste. A COVID-19 expõe como o funcionamento habitual do mercado de trabalho articula-se aos papéis de gênero para exigir mais trabalho das mulheres do que dos homens.
Apesar dos pontos críticos assinalados, o momento atual pode favorecer o debate sobre a necessidade de políticas que repensem as bases de responsabilidade da sociedade pelo trabalho doméstico. Isso pode auxiliar na busca de mecanismos de socialização desse trabalho. Políticas públicas nessa direção são muito necessárias. Orientações para essas ações devem incidir, pelo menos, em duas direções. A primeira deve focalizar a reorganização do trabalho doméstico apoiado na divisão igualitária de atribuições entre homens e mulheres; a segunda inclui a socialização dessas atividades por meio de dispositivos e equipamentos sociais de apoio na comunidade.

Como política pública para a reorganização desse trabalho, cabe a incorporação de habilidades no processo de formação e ensino desde a educação infantil. Ações básicas de autocuidado (como limpar a casa, lavar roupas e cozinhar) devem ser incorporadas à educação e reforçadas ao longo da trajetória escolar, com base na ideia de que as atividades de cuidado, que permitem suprir as necessidades básicas da própria existência, são tarefas "de menina" e "de menino" e representam habilidades a serem desenvolvidas na busca de autonomia e independência pessoal. Vários países do norte da Europa mantêm disciplinas com esse formato nos currículos escolares obrigatórios.

A outra vertente crucial nas ações e políticas públicas refere-se ao papel do Estado na oferta e/ou no incentivo à estruturação de equipamentos acessíveis para a socialização do trabalho doméstico. Mesmo considerando as medidas de distanciamento social atuais, ressalta-se a relevância de equipamentos como creches, lavanderias e restaurantes populares como dispositivos essenciais nesse processo e, apesar de serem alternativas que podem não estar em funcionamento no momento da pandemia, são medidas fundamentais para um equacionamento futuro mais definitivo do problema. As políticas públicas devem garantir ou fomentar a oferta desses equipamentos a todas as comunidades, em especial àquelas com vulnerabilidades sociais. Em geral, nas sociedades capitalistas, em especial em contextos como o brasileiro, apenas o trabalho produtivo (de bens e produtos) é compreendido como passível de ser socialmente dividido. Apesar do papel central do trabalho doméstico na reprodução social, ele permanece confinado no âmbito privado - como responsabilidade de cada família. Assim, movimentos na direção da socialização do trabalho doméstico são cruciais para redimensionar a vida e reduzir as desigualdades.

Há uma perspectiva de que a pandemia de COVID-19 afetará a frequência do TR ${ }^{20,21}$. Com a pandemia, no Brasil, o TR passou a ser adotado em ocupações em que esse tipo de trabalho não existia, a exemplo do ensino fundamental. Assim, mesmo na 
ausência de dados empíricos, é possível supor que as experiências forçadas neste primeiro momento se tornem, em seguida, atividades programadas, incorporadas a muitos postos de trabalho, em jornadas parciais ou integrais. Os estudos evidenciam certa aderência inicial a essa proposta de TR. Por exemplo, na Polônia, 40\% dos entrevistados declararam desejar permanecer com esse trabalho em 1-2 dias na semana; enquanto apenas 5,5\% não gostariam de manter TR depois da pandemia ${ }^{20}$. O acompanhamento dessa aderência possibilitará observar se será persistente.

A flexibilidade apregoada pelo TR em geral vem com o custo da ausência de limites temporais e espaciais do trabalho profissional e das tarefas domésticas e familiares. O elemento mais destacado é o caráter benéfico do TR na conciliação dessas atividades. Mas essa análise, como discutido, tem sido feita sem abordar diferenciais relativos à divisão sexual do trabalho nas sociedades. Também não se analisam a situação da pandemia e a crise econômica a ela associada. As características étnicas e raciais e de classes não são analisadas ou conhecidas.

Dada a tendência de ampliação do TR, cabe, então, discutir em que bases isso se dará. Há elementos que apontam a possibilidade de que o trabalho em casa contribua para o crescimento da precariedade do trabalho. A transição para o TR tem gerado custos adicionais aos trabalhadores(as) (compra de computadores, monitores, contratação de sistemas de internet e telecomunicações) e demandado espaço específico em casa onde se possa trabalhar com tranquilidade por longos períodos de tempo - o que é impossível para parte significativa da população trabalhadora com suas casas pequenas, apartamentos minúsculos e compartilhados. Será isso mais um marcador de exclusão do mercado de trabalho? O TR será a nossa antessala do teletrabalho (esse trabalho flexível, por tarefa, incorporado pela reforma trabalhista brasileira)?

Com relação à gestão do tempo, a situação exigirá conjunto de medidas para regulamentar e regular o trabalho em casa e deverá envolver investimentos em treinamento técnico e desenvolvimento de habilidades para as novas demandas, redesenho das atividades ao novo modelo e regras sobre as jornadas de trabalho. É importante frisar que esses limites não podem depender apenas de regulação trabalhador-empregador. O Estado, com políticas públicas de emprego e proteção do trabalho, tem papel central nessa regulação. De qualquer forma, há limites gigantescos para a regulação do trabalho no espaço privado da casa.

Ainda temos mais perguntas que respostas. $\mathrm{O}$ que parece salutar, no entanto, é que devem ser adotadas medidas que se antecipem a essas mudanças e criem estruturas que maximizem os benefícios potenciais do TR e protejam a saúde de trabalhadores e trabalhadoras. A correlação de forças no Brasil, neste momento, não tem sido favorável aos trabalhadores(as), observando-se amplo desmantelamento da proteção do trabalho ${ }^{47}$. Portanto, esse é mais um campo de lutas que se apresenta.

Por fim, cabe destacar que manter a vida, a saúde física e mental, é tarefa coletiva. É na capacidade de coesão social que reside a possibilidade de remodelar os contextos e seus processos para a redução de desigualdades. As ações de sindicatos, associações, coletivos e comunidades devem ser motivadas e fortalecidas. O projeto de sociedade brasileira igualitária e democrática ou excludente e autoritária está em disputa, sendo necessário que, individual e coletivamente, decida-se onde serão investidos os esforços e em que direção devem seguir nossos movimentos. É uma decisão destes tempos.

\section{Contribuições de autoria}

As autoras contribuíram igualmente para o planejamento, desenvolvimento, revisão crítica e aprovação da versão final publicada e assumem integral responsabilidade pelo trabalho realizado e o conteúdo aqui publicado.

\section{Referências}

1. Pinho PS, Araújo TM. Associação entre sobrecarga doméstica e transtornos mentais comuns em mulheres. Rev Bras Epidemiol. 2012;15(3):560-72.

2. Bilac ED. Trabalho e família: articulações possíveis. Tempo Soc. 2014;26(1):129-45.

3. Griep RH, Toivanen S, Santos IS, Rotenberg L, Juvanhol LL, Goulart AC, et al. Work-family conflict, lack of time for personal care and leisure, and job strain in migraine: results of the Brazilian Longitudinal Study of Adult Health (ELSA-Brasil). Am J Ind Med. 2016;59(11):987-1000.

4. Hirata H, Kergoat D. Divisão sexual do trabalho profissional e doméstico: Brasil, França, Japão. In: Costa AO, Sorj B, Bruschini C, Hirata H, organizadores. Mercado de trabalho e gênero: comparações internacionais. Rio de Janeiro: FGV Editora; 2008. p. 263-78. 
5. Coimbra R. Fundamentos e evolução da limitação constitucional da duração do tempo de trabalho no Brasil. e-Pública. 2016;3(1):184-206.

6. Ávila MB. Vida cotidiana e o uso do tempo pelas mulheres. $8^{\circ}$ Congresso Luso-Afro-Brasileiro de Ciências Sociais; Coimbra, 16-18 set. 2004. Coimbra: Universidade de Coimbra; 2004.

7. Hirata H, Kergoat D. Novas configurações da divisão sexual do trabalho. Cad Pesqui. 2007;37(132):595-609.

8. Bourdieu P. A dominação masculina. Kuhner MH, tradutora. 2. ed. Rio de Janeiro: Bertrand Brasil; 2002.

9. Thompson JB. Ideologia e cultura moderna. 5. ed. Petrópolis: Vozes; 2000.

10. Ávila MBM. O tempo do trabalho das empregadas domésticas: tensões entre dominação/exploração e resistência [tese]. Recife: Universidade Federal de Pernambuco; 2010. 321 p.

11. Instituto Brasileiro de Geografia e Estatística. Pesquisa Nacional por Amostra de Domicílios: PNAD COVID-19: maio/2020: Resultado mensal [Internet]. Rio de Janeiro: IBGE; 2020 [citado em 15 nov. 20]. Disponível em: https://biblioteca.ibge. gov.br/visualizacao/livros/liv101727.pdf

12. Gallardo Moya R. El viejo y el nuevo trabajo a domicilio: de la máquina de hilar al ordenador. Madrid: Ibidem; 1998.

13. Steil AV, Barcia RM. Um modelo para análise da prontidão organizacional para implantar o teletrabalho. Rev Adm. 2001;36(1):74-84.

14. Rocha CTM, Amador FS. O teletrabalho: conceituação e questões para análise. Cad EBAPE. BR. 2018;16(1):152-62.

15. Nilles JM, Carlson FR, Gray P, Hanneman GF. The telecommunications-transportation tradeoff: options for tomorrow. New York: John Wiley \& Sons; 1976.

16. Pinsonneault A, Boisvert M. The impacts of telecommuting on organizations and individuals: a review of the literature. In: Johnson NJ. Telecommuting and virtual offices: issues and opportunities. London: Idea Group; 2000. p. 163-85.

17. Kugelmass J. Telecommuting: a manager's guide to flexible work arrangements. Lanham: Lexington Books; 1995.

18. Brasil. Lei no 13.467, de 13 de julho de 2017. Altera a Consolidação das Leis do Trabalho (CLT), aprovada pelo Decreto-Lei $\mathrm{n}^{\circ} 5.452$, de $1^{\circ}$ de maio de 1943, e as Leis $\mathrm{n}^{\circ} 6.019$, de 3 de janeiro de 1974, 8.036, de 11 de maio de 1990 , e 8.212 , de 24 de julho de 1991, a fim de adequar a legislação às novas relações de trabalho. Diário Oficial da União [Internet]. 14 set. 2017. [citado em 20 set. 2020];1:1. Disponível em: http://www.planalto.gov.br/ ccivil_03/_ato2015-2018/2017/lei/L13467.htm

19. Szluz B. Telepraca - nowoczesna, elastyczna forma zatrudnienia i organizacji pracy - szansa czy zagrośenie? Modern Management Review. 2013;20(4):253-66.

20. Dolot A. Wpływ pandemii Covid-19 na pracę zdalną - perspektywapracownika. e-mentor. 2020;1(83):35-43.

21. Brynjolfsson E, Horton JJ, Ozimek A, Rock D, Sharma G, TuYe HY. Covid-19 and remote work: an early look at US data. NBER Working Paper Series[Internet]. 2020 [citado em 3 mar. 2021];27344:1-26. Disponível em: https:// www.nber.org/system/files/working_papers/ w27344/w27344.pdf

22. Góes G, Martins F, Sena JA. Nota técnica: Teletrabalho na pandemia: efetivo versus potencial. Carta de Conjuntura IPEA [Internet]. 2020 [citado em 3 mar. 2021];48:1-7. Disponível em: https:// www.ipea.gov.br/portal/images/stories/PDFs/ conjuntura/200707_nt_48_teletrabalho.pdf

23. Lameiras MAP, Cavalcanti MAFH. Mercado de Trabalho: PNAD COVID-19: Divulgação de 17/7/2020: Principais destaques. Carta de Conjuntura IPEA [Internet]. 2020 [citado em 3 mar. 2021];48:1-5. Disponível em: https:// www.ipea.gov.br/portal/images/stories/PDFs/ conjuntura/200717_cc_48_pnad_covid_1707.pdf

24. Alon T, Doepke M, Olmstead-Rumsey J, Tertilt M. The impact of Covid-19 on gender equality. NBER Working Paper Series [Internet]. 2020 [citado em 3 mar. 2021];26947:1-39. Disponível em: https:// www.nber.org/system/files/working_papers/ w26947/w26947.pdf

25. Himawan KK, Fanggidae JP, Helmi J. The sociocultural barriers of work-from-home arrangement due to Covid-19 pandemic in Asia: implications and future implementation. Advance [Preprint]. 2020 [citado em 3 mar. 2021]. Disponível em: https://advance.sagepub.com/ articles/preprint/The_Sociocultural_Barriers of Work-From-Home Arrangement Due to CŌVID-19_Pandemic_in_Asia_Implications_and_ Future_Implementation/12250190

26. Kaushik M, Guleria N. The impact of pandemic COVID-19 in workplace. EJBM. 2020;12(15):9-18.

27. Mungkasa O. Bekerja dari rumah (working from home/WFH): menuju tatanan Baru era pandemi Covid 19. Jurnal Perencanaan Pembangunan. 2020;4(2):126-50.

28. Wolor CW, Dalimunthe S, Febrilia I, Martono S. How to manage stress experienced by employees when working from home due to the Covid-19 virus outbreak. International Journal of Advanced Science and Technology. 2020;29(5):8359-64.

29. Putro SS, Riyanto S. How Asian sandwich generation managing stress in telecommuting during Covid-19 pandemic. IJSRED . 2020;3(3):485-92.

30. Gondim S, Borges LO. Significados e sentidos do trabalho do home-office: desafios para a regulação emocional. Orientações técnicas para o trabalho de psicólogas e psicólogos no contexto 
da crise COVID-19 [Internet]. Brasília, DF: SBPOT; 2020 [citado em 3 mar. 2021]. Disponível em: https://www.sbpot.org.br/central-deconteudo-covid19/wp-content/uploads/2020/04/ SBPOT_TEMATICA_5_Gondim_Borges.pdf

31. Cho E. Examining boundaries to understand the impact of COVID-19 on vocational behaviors. J Vocat Behav. 2020;119 (editorial 103437).

32. Bouziri H, Smith DRM, Descatha A, Dab W, Jean K. Working from home in the time of covid-19: how to best preserve occupational health? Occup Environ Med. 2020;77(7):509-10.

33. Lord P. The social perils and promise of remote work. JBEP. 2020;4:63-7.

34. Baert S, Lippens L, Moens E, Weytjens J, Sterkens P. The Covid-19 crisis and telework: a research survey on experiences, expectations and hopes. IZA Discussion Papers. 2020;132291-36.

35. Bahn K, Cohen J, Rodgers YM. A feminist perspective on COVID-19 and the value of care work globally. Gender Work Organ. 2020;27:695-9.

36. Nash M, Churchill B. Caring during COVID-19: a gendered analysis of Australian university responses to managing remote working and caring responsibilities. Gender Work Organ. 2020;27:833-46.

37. Hupkau C, Petrongolo B. Work, care and gender during the Covid-19 crisis. A CEP Covid-19 analysis [Internet]. 2020 [citado em 3 mar. 2021];2:1-12. Disponível em: https://cep.lse. ac.uk/pubs/download/cepcovid-19-002.pdf

38. Barajas MPL. Avanços na América Latina na medição e valoração do trabalho não remunerado realizado pelas mulheres. In: Fontoura N, Araújo C, organizadoras. Uso do tempo e gênero. Rio de Janeiro: EdUERJ; 2016. p. 21-42.
39. Pinto KA, Menezes GMS, Griep RH, Lima KTRS, Almeida MC, Aquino EML. Conflito trabalhofamília e uso do tempo: avaliação psicométrica de um instrumento no ELSA-Brasil. Rev Saude Publica. 2016;50:39.

40. Taub A. A new Covid-19 crisis: domestic abuse rises worldwide. The New York Times [Internet]. 6 abr. 2020 [citado em 3 mar. 2021]. Disponível em: https://www.nytimes.com/2020/04/06/world/ coronavirus-domestic-violence.html

41. Bradbury-Jones C, Isham L. The pandemic paradox: the consequences of COVID-19 on domestic violence. J Clin Nurs. 2020;29:2047-9.

42. Fórum Brasileiro de Segurança Pública. Nota técnica: violência doméstica durante a pandemia de Covid-19 [Internet]. 2020 [citado em 3 mar. 2021]. Disponível em: https://forumseguranca.org.br/wp-content/ uploads/2018/05/violencia-domestica-covid-19-v3.pdf

43. Frederickson M. COVID-19's gendered impact on academic productivity. GitHub [Internet]. 2020 [citado em 3 mar. 2021]. Disponível em: https:// github.com/drfreder/pandemic-pub-bias/blob/ master/README.md

44. Gabster BP, Daalen K, Dhatt R, Barry M. Challenges for the female academic during the COVID-19 pandemic. Lancet. 2020;395(10242):1968-70.

45. Castro B, Chaguri M. Um tempo só para si: gênero, pandemia e uma política científica feminista. Dados [Internet]. 22 maio 2020 [citado em 3 mar. 2021]. Disponível em: http://dados.iesp.uerj. $\mathrm{br} /$ pandemia-cientifica-feminista/

46. Andersen JP, Nielsen MW, Simone NL, Lewiss RE, Jagsi R. Meta-research: COVID-19 medical papers have fewer women first authors than expected. eLife. 2020;9: e58807.

47. Antunes R. Coronavírus: o trabalho sob fogo cruzado. São Paulo: Boitempo; 2020. 